\title{
Hydrogen bonding in thiobenzamide synthon and its Cadmium complex: Crystal structure and Hirshfeld analysis
}

\author{
INES RIGANE*, SIWAR WALHA and ABDELHAMID BEN SALAH \\ Laboratoire des Sciences des Matériaux et de L'environnement, Faculté des Sciences de Sfax, \\ Université de Sfax, B.P. 1171, 3000 Sfax, Tunisie \\ e-mail: inesrigane@gmail.com
}

MS received 4 February 2016; revised 27 May 2016; accepted 24 June 2016

\begin{abstract}
The thiobenzamid TBA and its Cd(II) complex, dichlorothiobenzamidecadmium(II) [Cd(TBA) $\left.\mathrm{Cl}_{2}\right]$ complex has been synthesized and characterized by FT-IR, FT-Raman and UV-Vis spectroscopy. The crystal and molecular structure of TBA and $\left[\mathrm{Cd}(\mathrm{TBA}) \mathrm{Cl}_{2}\right]$ were determined by single crystal X-ray diffraction analysis. The molecular arrangement in the crystal structure of TBA can be described on the basis of supramolecular dimeric synthons built up by four independent TBA molecules stacked via N-H. . .S hydrogen bonds. The 3D Hirshfeld surfaces and the associated 2D fingerprint plots were investigated for intermolecular interactions. The N-H. . .S hydrogen bond percentages were estimated to be $23.1 \%, 22.9 \%, 30.6 \%$ and $27.3 \%$ of Hirshfeld surfaces area respectively for each TBA molecule. Synthons are associated through $\mathrm{C}-\mathrm{H} . . . \pi$ interactions at percentage of $33.8 \%, 38.2 \%, 24.3 \%$ and $19.4 \%$ to result in 3D network. The dichlorothiobenzamide cadmium(II) complex bonded by sulfur atom of thiobenzamide shows a double chain of distorted octahedra around the cadmium atoms running along the $a$ axis and the packing is stabilized by intra- and inter-chain hydrogen bonding interactions of the type $\mathrm{N}-\mathrm{H} . . . \mathrm{Cl}$ and aromatic $\pi$. . $\pi$ stacking interactions between ring centroids at $21.8 \%$ and $7.6 \%$ of the Hirshfeld surface area, respectively. The decomposition of the complex to cadmium sulfide has been investigated by thermogravimetric analysis (TGA).
\end{abstract}

Keywords. Thiobenzamide; hydrogen bonding synthon; Cd(II); single crystal structure; hirshfeld surfaces.

\section{Introduction}

Thioamide ligands and their complexes are known to show a wide range of applications due to pharmacological properties, ${ }^{1-3}$ in biological activities like bactericidal, fungicidal, antibacterial, antifungal herbicidal and insecticidal functions. ${ }^{4-6}$ Their biological activities are shown to be due to their capacity to form chelates with metal ions. ${ }^{7}$ In addition, thioamides coordinate with metal ions in many different bridging modes to generate supramolecular networks with versatile molecular topologies endorsed by extensive functionalities. ${ }^{8-13}$ These ligands are also of immense interest because they are capable of functioning as hydrogen bond donors and/or acceptors. Thiobenzamid (TBA) is one such typical ligand. TBA and its derivatives stabilize the crystal packing by hydrogen bond interactions and various weak dispersive forces such as $\pi \ldots \pi$ stacking and $\mathrm{C}-\mathrm{H} . . . \pi$ interactions. The design and properties of TBA complexes together with their evolution into more sophisticated linear, di or tri dimensional polymeric systems have not been extensively studied. There

\footnotetext{
*For correspondence
}

are only a few TBA based metal compounds for which the crystal structure is known. All of them are neutral TBA complexes $\left\{\mathrm{W}(\mathrm{CO})_{5} \mathrm{TBA},\left[\mathrm{Co}^{\mathrm{III}}(\mathrm{BA})_{2} \mathrm{en}\right)(\mathrm{TBA})_{2}\right]$ $\left.\left.\mathrm{PF}_{6},\left[\mathrm{Co}^{\mathrm{III}} \text { (acacen)(TBA) }\right)_{2}\right] \mathrm{ClO}_{4}\right\}$ where, $(B A)_{2}$ en: bis (benzoylacetone)-ethylenediimine dianion; acacen: bis (acetylacetone)ethylenediimine dianion) and $[\mathrm{Cu}(\mathrm{TBA})$ $\left.(\mathrm{PhCSNH}) \mathrm{Br}]_{2}\right\},{ }^{14-16}$ or TBA derivatives $\left\{\mathrm{ZnL}_{2}, \mathrm{Cd}\right.$ ( $p$-BrTBA) $\mathrm{L}_{2}$ and $\mathrm{Cd}(\mathrm{HL})_{2} \mathrm{~L}_{2}$ where, HL:N-(diisopropoxyphosphoryl)p-bromothiobenzamide) $\}.{ }^{17}$ The structure of mixed ligand compounds contain monomers in which TBA acts as monodentate ligand involving the sulfur atom. In this paper, we report the synthesis, structural characterization, TGA thermal analysis, IR, Raman, and UV spectroscopic analysis of a new cadmium complex with TBA: $\left[\mathrm{Cd}(\mathrm{TBA}) \mathrm{Cl}_{2}\right]$ along with the structural and Hirshfeld analysis studies of thiobenzamide (TBA).

\section{Experimental}

\subsection{Preparation of Compounds}

Thiobenzamide (Aldrich) $(1.37 \mathrm{~g} ; 0.01 \mathrm{~mol})$ in ethanol was refluxed for $6 \mathrm{~h}$. On keeping it overnight at room 
temperature, a very fine and transparent crystals suitable for X-ray diffraction was formed and filtered. The corresponding Cadmium complex was prepared by refluxing the ethanolic solution of TBA $(0.57 \mathrm{~g}$, $0.002 \mathrm{~mol}$ ) with an ethanolic solution of cadmium chloride (Aldrich) $(0.36 \mathrm{~g}, 0.002 \mathrm{~mol})$ for $2 \mathrm{~h}$. The complex $\left[\mathrm{Cd}(\mathrm{TBA}) \mathrm{Cl}_{2}\right]$ was obtained as high-quality needle shaped crystals by slow evaporation of its solution over a period of one day.

\subsection{Single-crystal data collection and structure determination}

$\mathrm{X}$-ray diffraction data for TBA and $\left[\mathrm{Cd}(\mathrm{TBA}) \mathrm{Cl}_{2}\right]$ were collected on Bruker Kappa ApexII CCD diffractometer equipped with a rotating anode generator and with MoK $\alpha$ radiation. Details of crystal data and the structural refinement data related to TBA and $\left[\mathrm{Cd}(\mathrm{TBA}) \mathrm{Cl}_{2}\right]$ are listed in Table 1. The structure of TBA was solved using direct methods, the structure of the complex was solved by Patterson method using the program SHELXS-97, ${ }^{18}$ and refinement were carried out by fullmatrix least squares on $\mathrm{F}^{2}$ with SHELXL-97. ${ }^{19}$ All non-hydrogen atoms were located from the difference Fourier maps and refined with anisotropic thermal parameters. All hydrogen atoms were geometrically fixed and refined using a riding model AFIX 43 for aromatic $\mathrm{C}-\mathrm{H}$ or amide $\mathrm{N}-\mathrm{H}$ and AFIX 93 for idealized terminal $\mathrm{X}=\mathrm{NH}_{2}$. All calculations were performed on PC computer using WINGX program. ${ }^{20}$ Molecular graphics were generated using the DIAMOND Version $2,{ }^{21}$ and MERCURY 2.4 software. ${ }^{22}$

\subsection{Instrumentation}

The infrared spectra were recorded on a Perkin Elmer (FT-IR) Paragon $1000 \mathrm{Pc}$ spectrometer in the range $4000-400 \mathrm{~cm}^{-1}$ using $\mathrm{KBr}$ pellets. The RAMAN spectra were recorded on Labram HR 800 (Horriba Jobin Yvon) spectrometer with red laser at $\lambda=633 \mathrm{~nm}$ in the range $4000-0 \mathrm{~cm}^{-1}$. The electronic spectra (200$800 \mathrm{~nm}$ ) were recorded in ethanol on a PG instruments Ltd T80 UV-Vis spectrophotometer. The thermal analysis TGA was performed using Perkin Elmer pyris 6 TGA instrument from $50^{\circ} \mathrm{C}$ to $800^{\circ} \mathrm{C}$ at heating rate of $10^{\circ} \mathrm{C} /$ min under nitrogen atmosphere.

Table 1. Crystal data and structure refinement parameters for TBA and $\left[\mathrm{Cd}(\mathrm{TBA}) \mathrm{Cl}_{2}\right]$.

\begin{tabular}{|c|c|c|}
\hline Parameters & TBA & {$\left[\mathrm{Cd}(\mathrm{TBA}) \mathrm{Cl}_{2}\right]$} \\
\hline Empirical formula & $\mathrm{C}_{7} \mathrm{H}_{7} \mathrm{NS}$ & $\mathrm{C}_{7} \mathrm{H}_{7} \mathrm{NSCdCl}_{2}$ \\
\hline Formula weight & $137(\mathrm{~g} / \mathrm{mol})$ & $320.2(\mathrm{~g} / \mathrm{mol})$ \\
\hline Temperature (K) & $293(2)$ & $296(2)$ \\
\hline$\lambda(\AA)$ & 0.71073 & 0.71073 \\
\hline Crystal system & Monoclinic & Monoclinic \\
\hline Space group & $\mathrm{P} 2{ }_{1} / \mathrm{c}$ & $\mathrm{P} 2{ }_{1} / \mathrm{c}$ \\
\hline a $(\AA)$ & $5.832(5)$ & $3.8821(3)$ \\
\hline b $(\AA)$ & $13.055(5)$ & $23.601(2)$ \\
\hline$c(\AA)$ & $36.496(5)$ & $11.0734(1)$ \\
\hline$\beta\left({ }^{\circ}\right)$ & $90.419(5)$ & $97.901(2)$ \\
\hline $\mathrm{V}\left(\AA^{3}\right)$ & $2776(3)$ & $1004.95(15)$ \\
\hline $\mathrm{Z}$ & 4 & 4 \\
\hline$\rho_{\text {calcd }}\left(\mathrm{g} / \mathrm{cm}^{3}\right)$ & 1.313 & 2.118 \\
\hline$\mu(\mathrm{mm}-1)$ & 0.367 & 2.855 \\
\hline $\mathrm{F}(000)$ & 1152 & 616 \\
\hline $2 \theta$ Range for data collection $\left(^{\circ}\right)$ & $1.12-26.40$ & $2.05-31.84$ \\
\hline \multirow[t]{3}{*}{ Limiting indices } & $-7 \leq \mathrm{h} \leq 7$ & $-5 \leq h \leq 5$ \\
\hline & $-16 \leq \mathrm{k} \leq 16$ & $-34 \leq \mathrm{k} \leq 34$ \\
\hline & $-44 \leq 1 \leq 45$ & $-16 \leq 1 \leq 13$ \\
\hline Reflections collected & 28576 & 7457 \\
\hline Independent reflections/R(int) & $5692 / 0.0962$ & $3395 / 0.0465$ \\
\hline Observed reflections $[\mathrm{I}>2 \sigma(\mathrm{I})]$ & 3057 & 2127 \\
\hline Goodness of fit & 1.052 & 0.94 \\
\hline \multirow[t]{2}{*}{ Final $\mathrm{R}$ indices $[\mathrm{I}>2 \sigma(\mathrm{I})]$} & $\mathrm{R} 1=0.0768$ & $\mathrm{R} 1=0.0405$ \\
\hline & $\mathrm{wR} 2=0.2028$ & $\mathrm{wR} 2=0.0663$ \\
\hline Measurement & Diffractometer Kappa APEX II & Diffractometer Kappa APEX II \\
\hline Scan mode & $\omega$ & $\omega$ \\
\hline CCDC number & 944106 & 944104 \\
\hline
\end{tabular}




\subsection{Hirshfeld surface analysis}

Hirshfeld surface analysis was performed to identify the types and regions of weak intermolecular interactions, and proportions of these interactions. Molecular Hirshfeld surface in crystal structure is constructed from the electron distribution. It can be compared to the van der Waals (vdW) surface which other molecules or atoms come into contact when interactions are present. The direction and strength of these interactions can be mapped onto the Hirshfeld surface using various descriptors, such as the normalized contact distance $\left(d_{\text {norm }}\right)$, displayed using a red-white-blue color scheme corresponding to negative value (red regions) and positive (blue regions) for contacts shorter and greater than vdW separations, respectively. The $d_{\text {norm }}$ is based on both distances of any surface point to the nearby interior $\left(d_{i}\right)$ and exterior $\left(d_{e}\right)$ atoms and the van der Waals radii of the atoms, as listed in the following equation.

$$
d_{n o r m}=\left(d_{i}-r_{i}^{v d w}\right) / r_{i}^{v d w}+\left(d_{e}-r_{e}^{v d w}\right) / r_{e}^{v d w}
$$

The combination of $d_{e}$ and $d_{i}$ in the form of 2D fingerprint plot provides summary of intermolecular contacts in the crystal. The Hirshfeld surfaces mapped with shape index range of -1.0 to $1.0 \AA$, $d_{\text {norm }}$ range of -0.5 to $1.5 \AA$, and full fingerprint plot were generated using the program CRYSTAL EXPLORER 3.1. ${ }^{23}$

\section{Results and discussion}

\subsection{Crystal structure description}

3.1a Thiobenzamide molecule (TBA): The molecular structure of TBA along with atom numbering scheme is given in Figure S1. Selected bond lengths and bond angles of TBA are given in Table S1. According to the X-ray data, TBA crystallizes in the monoclinic space group $\mathrm{P} 2{ }_{1} / \mathrm{c}$, the asymmetric unit contains four independent molecules with rigid benzene rings. The $\mathrm{C}-\mathrm{N}$ and $\mathrm{C}=\mathrm{S}$ bonds length range respectively from $1.311(7)$ to $1.334(7) \AA$ and $1.657(6)$ to $1.668(5)$, they are intermediate between ideal values of corresponding single and double bonds [C-N: $1.47 \AA],{ }^{24}$ $[\mathrm{C}=\mathrm{N}: 1.28 \AA]$ and [C-S: $1.82 \AA],[\mathrm{C}=\mathrm{S}: 1.56 \AA]$ giving evidence for an extended $\pi$ - delocalization along the benzene ring through $(\pi-\sigma-\pi)$ conjugation. These are similar to those observed in chloro, bromo and methyl thiobenzamide derivates. ${ }^{25-27}$ Whereas in the thiosemicarbazid molecule, ${ }^{28}$ the $\mathrm{C}=\mathrm{S}$ bond length is in the range of $1.707 \AA$ which is longer than those of TBA molecule, this is due to the substitution of carbon by nitrogen atom leading to an accurate conjugation $(\pi-\sigma-$ n) effect which is more important than $(\pi-\sigma-\pi)$. The mean deviations of the plane through the atoms of the ring emphasize the non-planar conformation of the four TBA molecules in the asymmetric unit with torsion angle between $-21.29^{\circ}$ and $40.59^{\circ}$. In general, TBA possesses a rigid benzene ring and will not be as flexible geometrically as the other chain-like structures but it prefers a non-planar structure. ${ }^{29}$

Exploring the crystal self-assembly of TBA, an interesting behavior is observed. The structural arrangement is stabilized by the intermolecular N-H. ..S contacts (Table 2). In Figure 1a, the supramolecular network is basically an infinite chain along $a$ axis, constructed by dimeric TBA molecules connected by N-H...S hydrogen bonding. Each TBA molecule acts as a double hydrogen-bond acceptor and donor for the amine and sulfur groups. Therefore, this molecular assembly allows us to observe alternated macro-ring pattern with a graph set motif of $\mathrm{R}_{2}^{2}(8)$ (Figure $1 \mathrm{~b}$ ).

A pronounced C-H... $\pi$ interactions is observed in the packing of dimeric chains (Table 3) these are certainly a direct consequence of the twist in crystal structure.

No acceptable $\pi \ldots \pi$ interactions are observed $\left(\mathrm{d}_{\mathrm{cg} . . . \mathrm{cg}}>4\right)$ because there is no face-to-face configuration for benzene rings.

3.1b $\left[C d(T B A) C l_{2}\right]$ : The molecular structure of the complex $\left[\mathrm{Cd}(\mathrm{TBA}) \mathrm{Cl}_{2}\right]$ is represented in Figure S2

Table 2. Hydrogen bonding parameters for TBA.

\begin{tabular}{|c|c|c|c|c|}
\hline & D-H $(\AA)$ & H. ..A $(\AA)$ & D. ..A $(\AA)$ & $<$ D-H. ..A $\left(\left(^{\circ}\right)\right.$ \\
\hline N3-HN32......S3 & 0.86 & 2.739 & $3.371(4)$ & 131.53 \\
\hline N3-HN31 .....S1 & 0.86 & 2.537 & $3.341(7)$ & 156.04 \\
\hline N2-HN21.....S2 & 0.86 & 2.690 & $3.289(3)$ & 127.90 \\
\hline N2-HN22......S4 & 0.86 & 2.645 & $3.494(8)$ & 169.42 \\
\hline N4-HN42. . . . .S4 & 0.86 & 2.688 & $3.329(4)$ & 132.45 \\
\hline N4-HN41 . . . . S2 & 0.86 & 2.579 & $3.381(8)$ & 155.52 \\
\hline N1-HN11.....S1 & 0.86 & 2.696 & $3.277(3)$ & 126.07 \\
\hline N1-HN12.....S3 & 0.86 & 2.670 & $3.521(9)$ & 170.50 \\
\hline
\end{tabular}




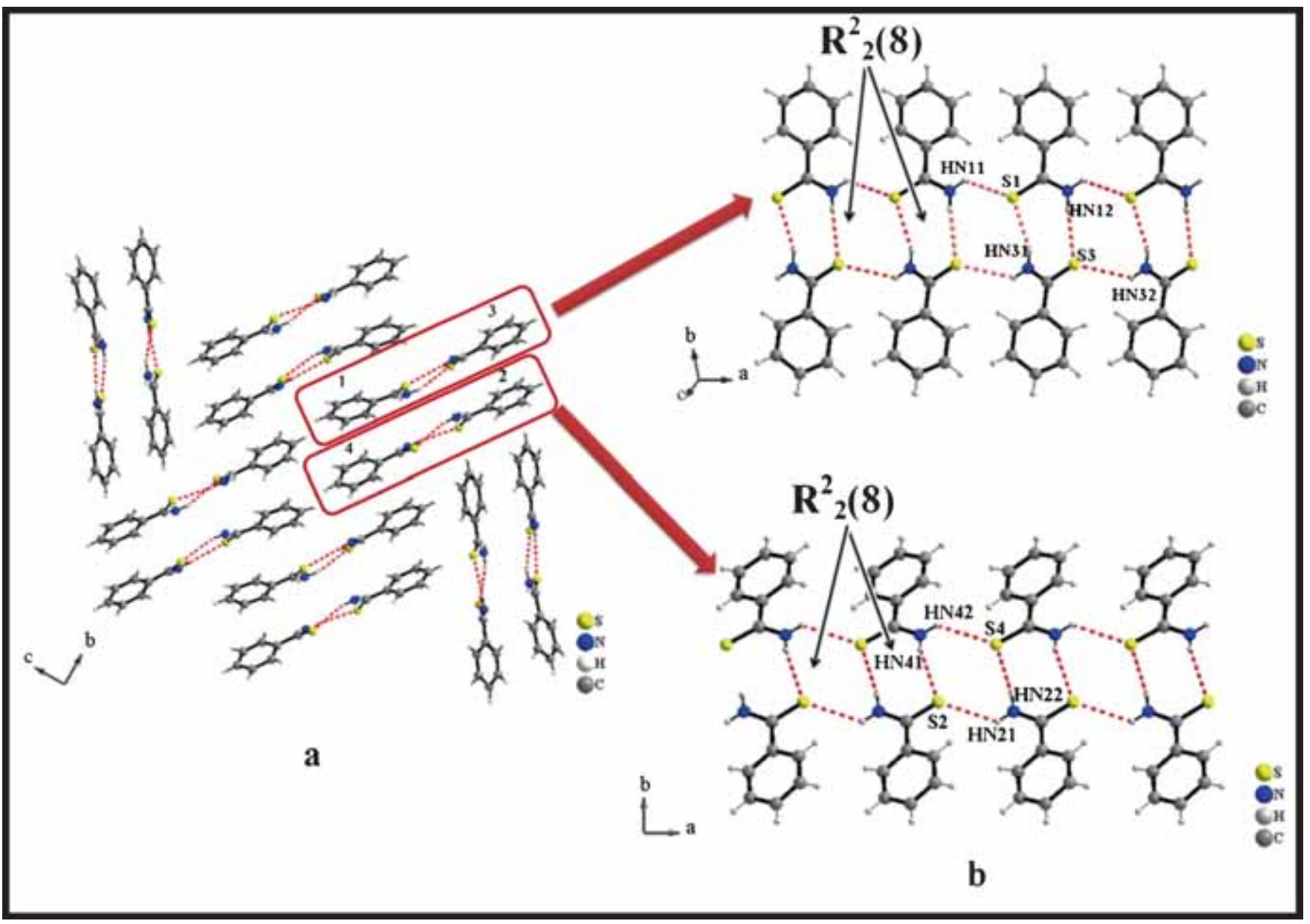

Figure 1. View of cyclic hydrogen bonds for TBA crystal structure.

Table 3. C-H. . . $\pi$ interaction parameters for TBA.

\begin{tabular}{lccc}
\hline $\mathrm{C}_{\mathrm{i}}-\mathrm{H}_{\mathrm{i}} \ldots \ldots \mathrm{cg}_{\mathrm{j}}$ & $\mathrm{H}_{\mathrm{i}} \ldots . . \mathrm{cg}_{\mathrm{j}}(\AA)$ & $\mathrm{C}_{\mathrm{i}}-\mathrm{cg}_{\mathrm{j}}(\AA)$ & $\mathrm{C}_{\mathrm{i}}-\mathrm{H}_{\mathrm{i}} \ldots . . \mathrm{cg}_{\mathrm{j}}\left(^{\circ}\right)$ \\
\hline $\mathrm{C}_{12}-\mathrm{H}_{12} \ldots \ldots \mathrm{cg}_{4}$ & 2.820 & 3.527 & 133.62 \\
$\mathrm{C}_{35}-\mathrm{H}_{35} \ldots . \mathrm{cg}_{2}$ & 3.015 & 3.599 & 122.34 \\
$\mathrm{C}_{24}-\mathrm{H}_{24} \ldots . \mathrm{cg}_{3}^{\mathrm{i}}$ & 2.954 & 3.721 & 140.70 \\
$\mathrm{C}_{25}-\mathrm{H}_{25} \ldots . \mathrm{cg}_{3}^{\mathrm{ii}}$ & 3.448 & 3.968 & 117.79 \\
$\mathrm{C}_{16}-\mathrm{H}_{16} \ldots . \mathrm{cg}_{2}^{\mathrm{iii}}$ & 3.047 & 3.773 & 136.11 \\
$\mathrm{C}_{26}-\mathrm{H}_{26} \ldots . \mathrm{cg}_{3}^{\mathrm{iv}}$ & 3.163 & 3.904 & 138.06 \\
\hline
\end{tabular}

Equivalent position code: $\mathbf{i}=2-\mathrm{x}, 1 / 2+\mathrm{y}, 1 / 2-\mathrm{z} ; \mathbf{i}=1-\mathrm{x}$, $1 / 2+y, 1 / 2-z ;$ iii $=1-x, 1 / 2+y, 5-z ;$ iv $=1-x, 1-y, 1-z$.

Cg1: centroid C11-C12-C13-C14-C15-C16; Cg2: centroid C21-C22-C23-C24-C25-C26

Cg3: centroid C31-C32-C33-C34-C35-C36; Cg4: centroid C41-C42-C43-C44-C45-C46

and selected bond lengths and bond angles are summarized in Table S2. The compound crystallizes in a monoclinic space group $\mathrm{P} 2{ }_{1} / \mathrm{c}$. The molecular structure of $\left[\mathrm{Cd}(\mathrm{TBA}) \mathrm{Cl}_{2}\right]$ obtained from single crystal $\mathrm{X}$-ray diffraction studies shows double chains of octahedra around the cadmium atoms running along the $a$ axis (Figure 2).
The environment around the metal atoms may be described as distorted octahedral geometry with four chloride atoms $\left(\mathrm{Cl} 2, \mathrm{Cl}^{2}, \mathrm{Cl}^{\mathrm{ii}}\right.$ and $\left.\mathrm{Cl} 1^{\mathrm{iii}}\right)$ in the equatorial plane and sulfur atom of the TBA ligand and another chloride atom (Cl1) in the axial position (equivalent position code: $\mathrm{i}=\mathrm{x}-1, \mathrm{y}, \mathrm{z}$; ii $=1-\mathrm{x}, 1-\mathrm{y}, 2-\mathrm{z}$; iii $=$ $2-x, 1-y, 2-z)$. The slight distortion from an ideal octahedral stereochemistry is suggested by the values for the orthogonal bite angles S-Cd-Cl2 $\left(91.63(4)^{\circ}\right)$ and $\mathrm{Cl} 2$ $\mathrm{Cd}-\mathrm{Cl} 1\left(89.07(3)^{\circ}\right)$. These $\mathrm{CdCl}_{5} \mathrm{~S}$ octahedra are held together to generate endless centrosymmetric double chains by sharing four common edges.

The dichlorothiobenzamide cadmium(II) structure presents a similar arrangement around $\mathrm{Cd}$ centers compared with $\mathrm{SrCd}_{2} \mathrm{Cl}_{6} .8 \mathrm{H}_{2} \mathrm{O}{ }^{30}$ The $\mathrm{Cd}-\mathrm{Cl}$ bonds length range from 2.64(1) to 2.72(1) $\AA$. The $\mathrm{Cd}-\mathrm{S}$ bond distance is $2.582(1) \AA$. The $\mathrm{C}=\mathrm{S}$ bond distance is slightly increased in the complex, when compared to the corresponding values in the free TBA, and this supports coordination. The $\mathrm{C}-\mathrm{N}$ bond length of 1.312(5) $\AA$ agrees well with that observed for a TBA free molecule, showing that the nitrogen atom has no interaction with the metal centre. As in the free molecule, TBA in the 


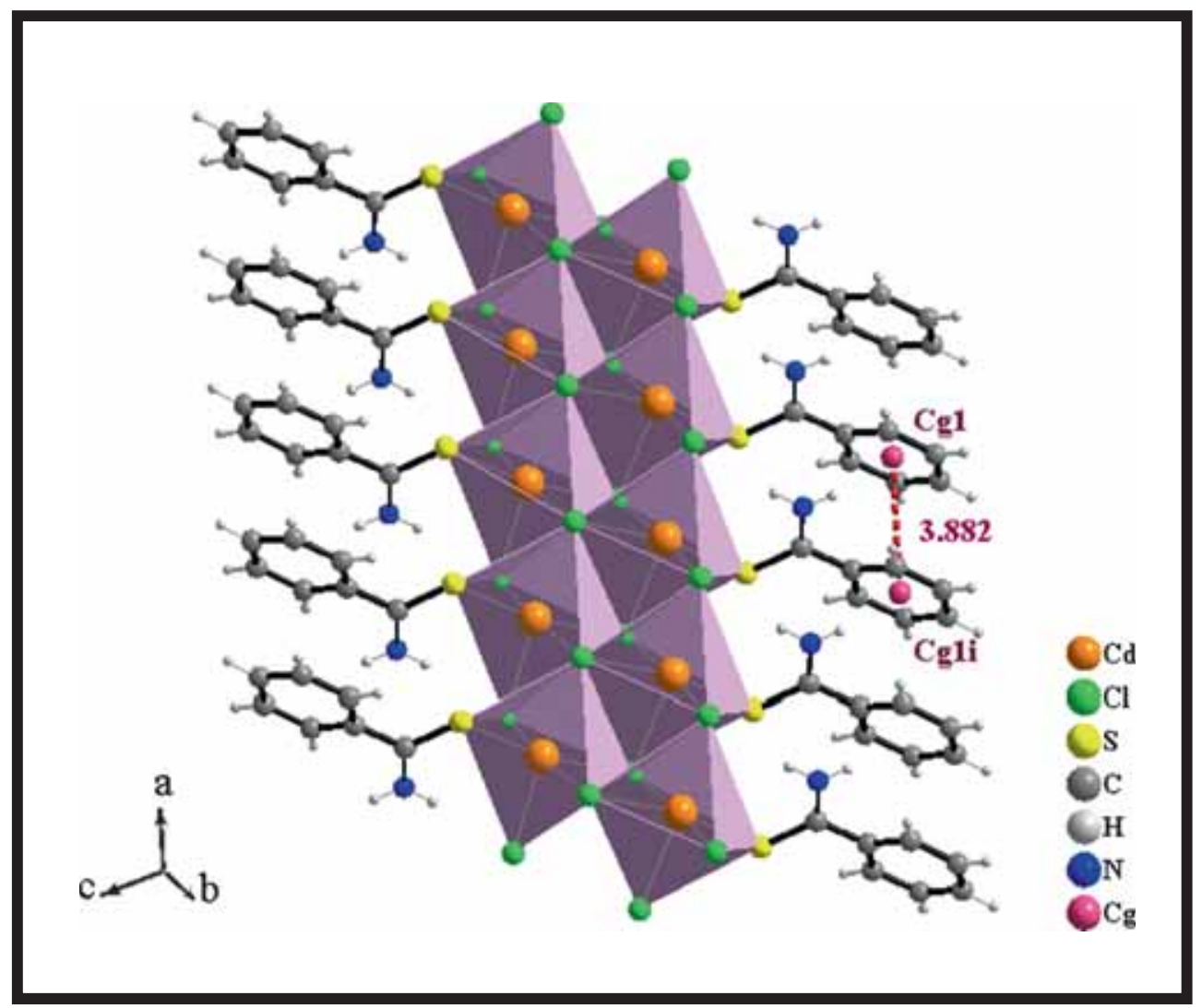

Figure 2. View of crystal structure of complex $\left[\mathrm{Cd}(\mathrm{TBA}) \mathrm{Cl}_{2}\right]$ including the $\pi$. . $\pi$ interactions between ring centroids 'cg'.

complex coordinated to the metal via the thione sulfur atom ion is non-planar with a torsion angle of $26.39^{\circ}$. In general, the TBA molecule behaves as a monodentate ligand through the sulfur atom even though it has bidentate character and this could be due to the steric effect.

Furthermore, the aromatic rings are correlated by $\pi . . \pi$ stacking interactions with centroid-centroid distance of $3.882 \AA$ to furnish a better stability through closed packing (Figure 2). This distance is comparable with reported compounds. ${ }^{31,32}$ The supramolecular structure is packed by intra- and inter-chains hydrogen bonding interactions of the type $\mathrm{N}-\mathrm{H}$. . . Cl (Table 4).

Each chain of dimer develops through the nitrogen atoms of the amino part of thiobenzamide two hydrogen bonds with chloride atoms leading to the formation of centrosymmetric association as layers of double chains (Figure 3). Besides, the combination of $\mathrm{N}-\mathrm{H}$. . . Cl hydrogen bonds forms pattern cycles $\mathrm{R}_{2}^{2}(8)$ containing two donors $(\mathrm{N})$ and two acceptors $(\mathrm{Cl})$ of hydrogen bonds.

Table 4. Interaction parameters of the compound $\left[\mathrm{Cd}(\mathrm{TBA}) \mathrm{Cl}_{2}\right]$.

\begin{tabular}{|c|c|c|c|c|}
\hline & D-H $(\AA)$ & H. . .A $(\AA)$ & D...A( $(\AA)$ & $<$ D-H...A( $\left(^{\circ}\right)$ \\
\hline N-HN1......Cl2 & 0.86 & 2.533 & $3.310(1)$ & 150.70 \\
\hline $\mathrm{N}-\mathrm{HN} 2 \ldots . . \mathrm{Cl} 2$ & 0.86 & 2.450 & $3.292(2)$ & 166.29 \\
\hline \multicolumn{5}{|c|}{$\pi-\pi$ interaction } \\
\hline \multicolumn{5}{|c|}{$\operatorname{cg} 1-\operatorname{cg} 1^{\mathrm{i}}(\AA)$} \\
\hline $\operatorname{cg} 1-\operatorname{cg} 1^{\mathrm{i}}$ & 3.882 & & & \\
\hline
\end{tabular}

Symmetry code: $\mathrm{i}=1+\mathrm{x}, \mathrm{y}, \mathrm{z} ; \mathrm{cg} 1$ : centroid C1-C2-C3-C4-C5-C6 ; $\operatorname{cg} 1^{\mathrm{i}}$ : centroid $\mathrm{C} 1^{\mathrm{i}}-\mathrm{C} 2^{\mathrm{i}}-\mathrm{C} 3^{\mathrm{i}}-\mathrm{C} 4^{\mathrm{i}}-\mathrm{C} 5^{\mathrm{i}}-\mathrm{C} 6^{\mathrm{i}}$

Where $\mathrm{Cg}$ refers to the ring center of gravity, $\operatorname{cg} 1-\operatorname{cg} 1^{\mathrm{i}}$ : distance between ring centroids 


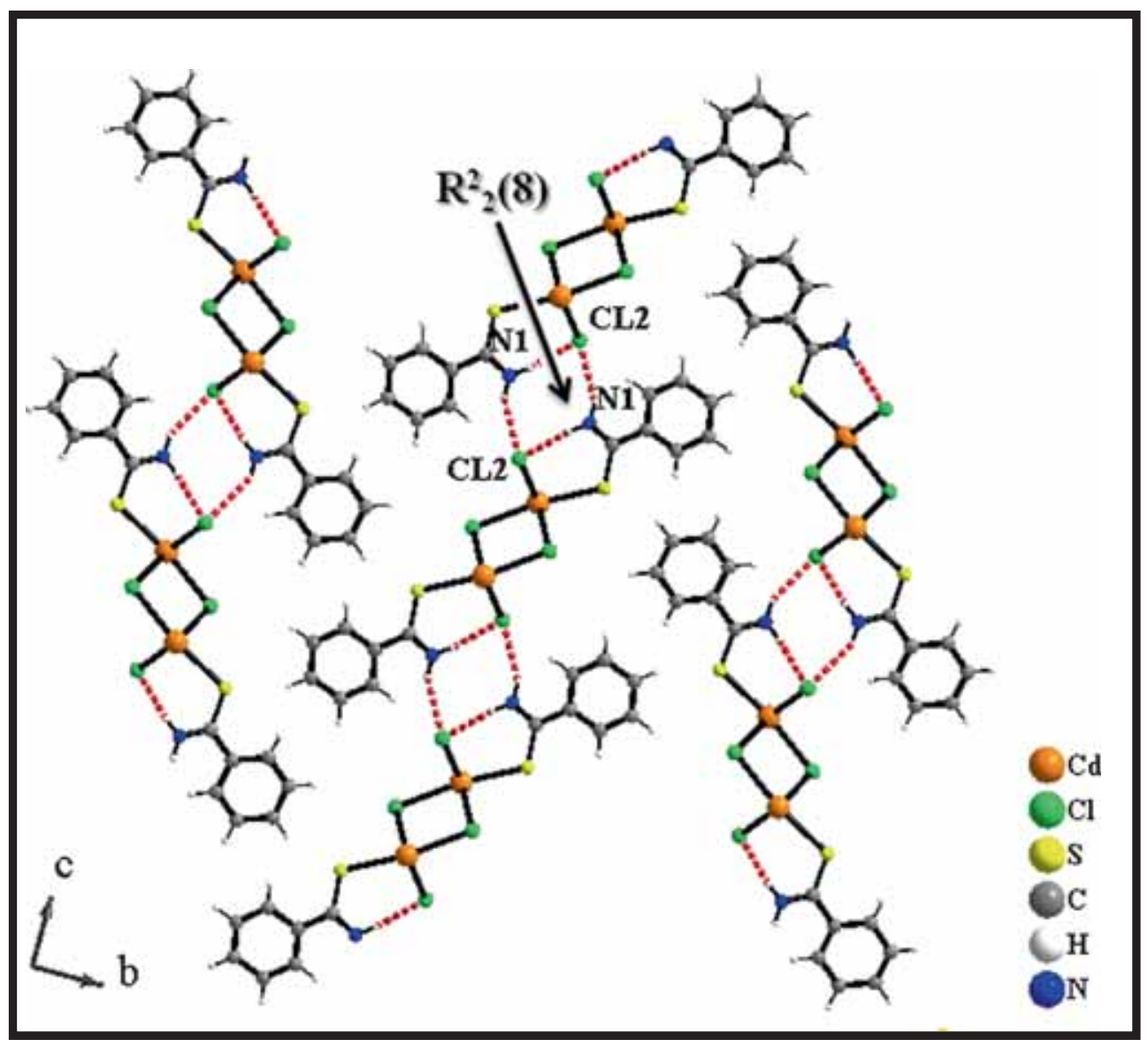

Figure 3. Interchain hydrogen bonding interactions of $\left[\mathrm{Cd}(\mathrm{TBA}) \mathrm{Cl}_{2}\right]$.

\subsection{Hirshfeld surface analysis: A deeper look into the} nature of the crystal packing forces

In order to profoundly evaluate various intermolecular interactions and their role for the crystal lattice stability, two different descriptors have been chosen for maps of shape index and $d_{\text {norm }}$.

The Hirshfeld surfaces of four independent molecules in an asymmetric unit in TBA structure have similar shapes (Figure 4) reflecting similar intermolecular contacts. Obviously, the related information in Tables 2 and 3 can be clearly corroborated in the Hirshfeld surfaces and 2D fingerprint plots. The interactions between the amino part of thiobenzamide $\mathrm{NH}_{2}$ and sulfur $\mathrm{S}$ atoms are shown as bright red areas (labeled 1) in the $d_{\text {norm }}$ surfaces forming hydrogen bonds of the type N-H...S. Deep red region on the shape index surfaces for TBA highlight the hydrogen bond acceptor (concave) labeled as (4), the blue region corresponds to the hydrogen bond donor (convex) indexed as (5) indicating the association of the TBA molecules on two pairs (1 and 3 ) and (2 and 4). Shape index has the very useful property for complementary surface pairs to identify complementary hollows and bumps where two molecular surfaces touch one another ${ }^{33}$ this is the case of adjacent molecules $(1,4)$ and $(2,3)$ with contacting regions of complementary red (concave) and blue (convex) shape index, labeled (2) and (3) respectively that characterize the C-H... interactions.

A visual inspection of fingerprint plots in the molecules of asymmetric unit for TBA reveals that the four molecules have nearly the same fingerprint plots with minor differences in the distribution of interaction (related $d_{e}$ and $d_{i}$ values) of the molecules in asymmetric unit. The diffuse blue region manifesting as a scattered point in the fingerprint plot is related to $\mathrm{H}$...H contacts (marked as 6) which accounts to nearly $40 \%$ of the total Hirshfeld surface area of each TBA molecule where molecule 1 and 4 show shorter H... H interaction $\left(d_{e}^{\text {min }}=d_{i}^{\text {min }}=1.2 \AA\right)$ than molecule 2 and 3 $\left(d_{e}^{\text {min }}=d_{i}^{\text {min }}=1.3 \AA\right)$. The intermolecular N-H. . S hydrogen bonds for the four molecules $1,2,3$ and 4 with $23.1 \%, 22.9 \%, 30.6 \%$ and $27.3 \%$ area of Hirshfeld surface contributions, respectively, appear as two long sharp spikes in the 2D fingerprint plots, the upper spike (where $d_{e}>d_{i}$ ) corresponds to the hydrogenbond donor (labeled as 7) and the lower spike (where 


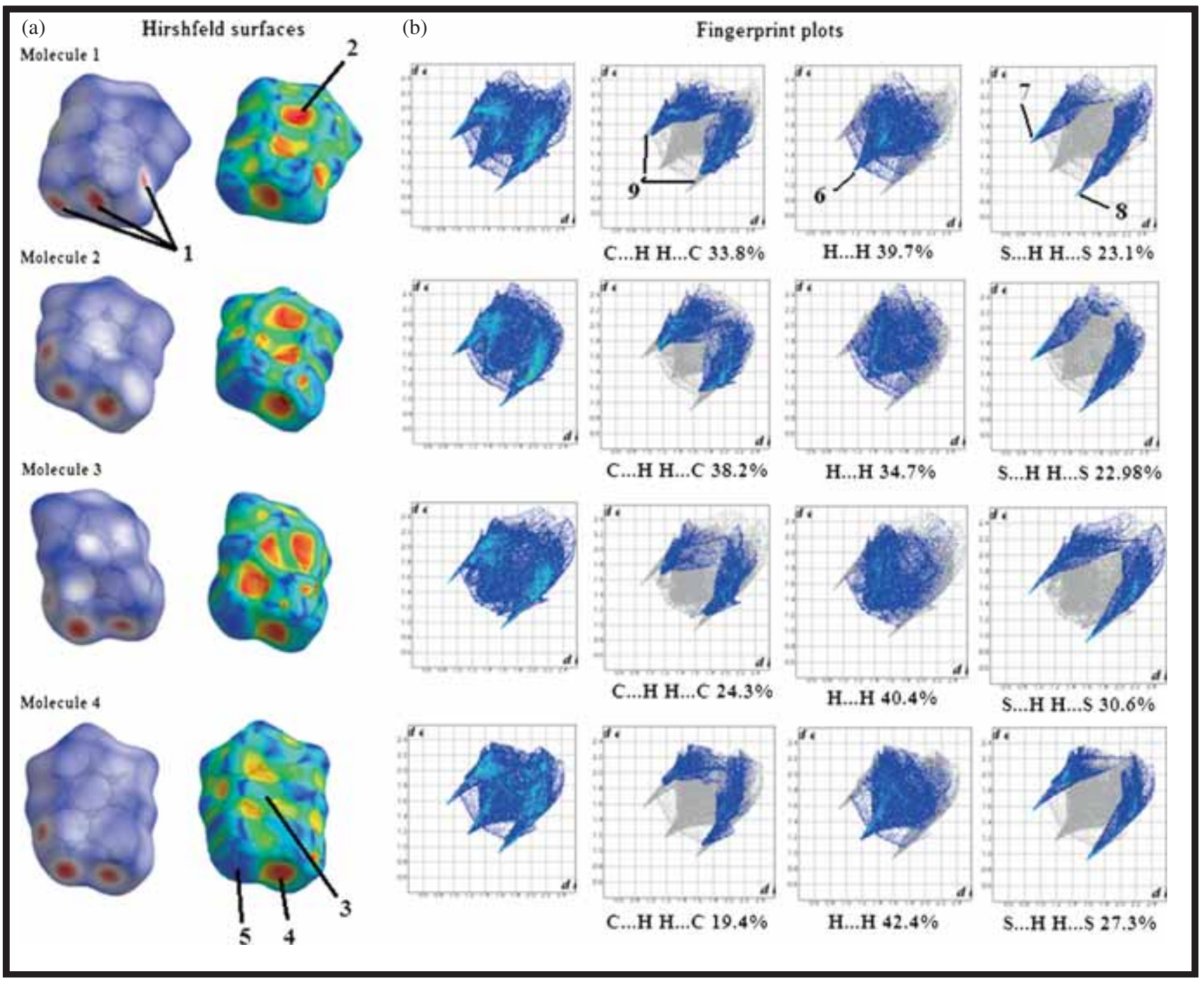

Figure 4. The $d_{\text {norm }}$ (a) and shape index (b) Hirshfeld surfaces and the fingerprint plots of the four independent molecules in TBA crystal.

$d_{e}<d_{i}$ ) corresponds to the hydrogen-bond acceptor (labeled as 8). Besides, the significant contributions from $\mathrm{C}-\mathrm{H} . . . \pi$ contacts in the crystal is reflected by two distinct short spikes indexed as 9 and present here with $33.8 \%, 38.2 \%, 24.3 \%$ and $19.4 \%$ proportion. Relative contributions of H...H, S...H, H. .C and C. ..H contacts to the Hirshfeld surface areas for TBA ligand are summarized in the histogram presented in Figure S3. In conclusion, the crystal packing of TBA is dominated by C-H. . . $\pi$, H. . .H interaction and N-H. . .S hydrogen bonds.

The Hirshfeld surfaces of the asymmetric unit of the compound $\left[\mathrm{Cd}(\mathrm{TBA}) \mathrm{Cl}_{2}\right]$ mapped with shape index and $d_{\text {norm }}$ are presented in Figure 5. The corresponding fingerprint plots for the interactions present in the complex were shown in Figure S5. The most obvious feature on the Hirshfeld surface of this complex is the pair of red dots on the $d_{\text {norm }}$ surface at the end of the molecule, arising from the hydrogen bonds $\mathrm{N}-\mathrm{H}$... Cl labeled as $\left(a_{1}\right)$ in Figure 5. The map of shape index clearly shows these depressions as large red regions of concave curvature (hydrogen-bond acceptor) $\left(\mathrm{c}_{1}\right)$, while $\mathrm{N}$ $\mathrm{H}$. . Cl hydrogen bond donor regions have exactly the opposite curvature and thus have shape index of equal magnitude and opposite sign $(\mathrm{Cl}$. . .N-H), and are blue (convex) $\left(\mathrm{c}_{2}\right)$. Furthermore, the $d_{\text {norm }}$ surface shows a large deeper red depression (Figure 5b) indicating a close contact between $\mathrm{Cd}(\mathrm{II})$ center and the chlorine atoms with neighboring unit, based on which the double chains of octahedra around the cadmium atoms is constructed. The pattern of red and blue triangles on the same region of the shape index surface is characteristic of $\pi-\pi$ stacking interaction between two phenyl rings (Figure 5c).

Figure S4 illustrates the analysis of the twodimensional fingerprint plots for $\left[\mathrm{Cd}(\mathrm{TBA}) \mathrm{Cl}_{2}\right]$ complex. 


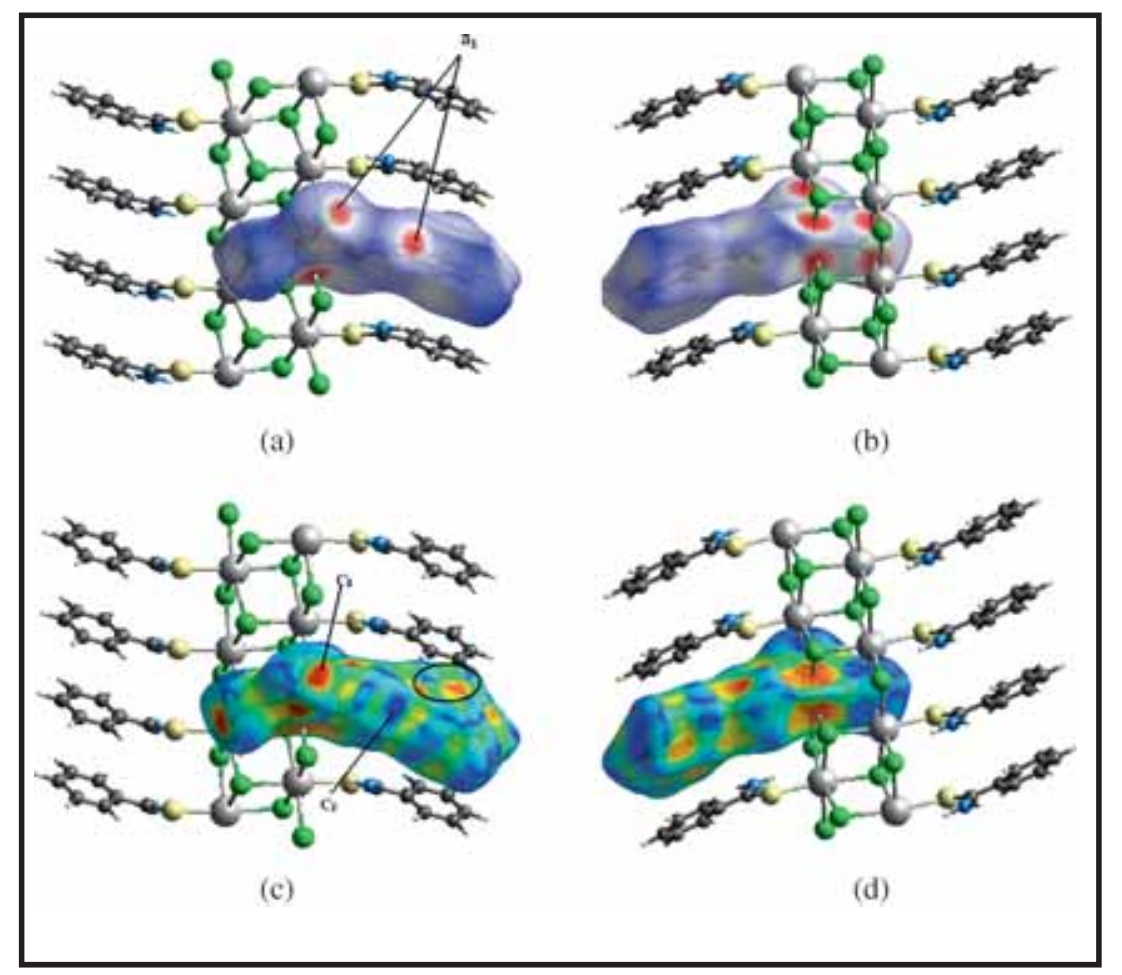

Figure 5. Hirshfeld surfaces mapped with $d_{\text {norm }}$ and shape index of $\left[\mathrm{Cd}(\mathrm{TBA}) \mathrm{Cl}_{2}\right]$.

The red streak in the middle of the plot (Figure S4(i)) shows the increasingly important contribution from $\mathrm{H}$... H intermolecular contacts $(27.5 \%)$, which is the most relative to the other contact in the crystal and showed up as a characteristic spike in the fingerprint plot where $d_{e}=d_{i} \approx 1.2 \AA$.

The fingerprint plot corresponding to the C...C interaction reveals that the lowest values for $d_{e}$ and $d_{i}$ is $1.9 \AA$ each so $1.9+1.9=3.8 \AA$, characterizing the $\pi \ldots \pi$ interaction between ring centroids along $a$ axis. Figure S4 (iv) shows this interaction as a region of pale blue/green colour on the diagonal with $7.6 \%$. A third principal interaction identifiable in Figure S4(iii) is due to $\mathrm{Cl}$. . .H hydrogen bonds, and shows up as a symmetric pair of long sharp spikes characteristic of a strong paired intermolecular hydrogen bond, the upper one (where $d_{e}>d_{i}$ ) associated with the donor (N-H...Cl), the lower one (where $d_{e}<d_{i}$ ) with the acceptor $(\mathrm{Cl} \ldots \mathrm{N}-\mathrm{H})$, the percentage share of the $\mathrm{Cl} \ldots \mathrm{H} / \mathrm{H}$. . Cl interaction in the total fingerprint plot is $21.8 \%$. The S. . .H contacts are also present with $9.5 \%$ to furnish the final 3-D architecture in the crystal structure. Finally, diffuse blue regions characterize the fingerprint plot patterns; these regions result from a small part of the surface with long distances to the nearest atoms and indicate a less than ideal packing arrangement for the molecule in the crystal. ${ }^{34}$

\subsection{Spectroscopy}

The TBA ligand and the $\left[\mathrm{Cd}(\mathrm{TBA}) \mathrm{Cl}_{2}\right]$ complex have been characterized by recording their IR spectra (Figure $\mathrm{S} 5$ and $\mathrm{S} 6)$. The $v(\mathrm{C}=\mathrm{S})$ band of the free ligand at $1133-1073 \mathrm{~cm}^{-1}$ is found to be shifted to lower energies $\left(1000 \mathrm{~cm}^{-1}\right)$ in the spectra of the complex. The appearance of a band at $215 \mathrm{~cm}^{-1}$ that can be assigned to $v(\mathrm{Cd}-\mathrm{S})$ stretching in the Raman spectrum of the complex (Figure S7) provides a strong evidence for the coordination of the sulfur atom to the central metal. Whereas, the band assigned to the amino part of thiobenzamide group which appears at $3502-3346 \mathrm{~cm}^{-1}$ in the free ligand, remains unchanged in the complex spectra confirming and indicating its noninvolvement in coordination.

The UV-Vis spectrum (Figure S8) of TBA and its cadmium complex showed two absorption bands in the ultraviolet region. The first band appeared around $240 \mathrm{~nm}$ is related to the $\pi \rightarrow \pi *$ transitions of the benzene rings. ${ }^{35}$ While the last band around $290 \mathrm{~nm}$ may be due to the $n \rightarrow \pi^{*}$ transitions associated with the thiocarbonyl group. The complex shows no appreciable absorption in the region $\lambda>450 \mathrm{~nm}$ in ethanol solution, in accordance with the $\mathrm{d}^{10}$ electronic configuration of the $\mathrm{Cd}(\mathrm{II})$ ions which shows only the charge transfer transitions between the ligand and the metal, no d-d transition are expected for $\mathrm{d}^{10}$ metal complexes. ${ }^{36}$ 


\subsection{Thermal behavior of $\left[\mathrm{Cd}(\mathrm{TBA}) \mathrm{Cl}_{2}\right]$}

Several complexes of Cadmium with sulfur- containing ligands have been used as precursors to synthesize CdS nanoparticules. ${ }^{37,38}$ Accordingly, thermal stability of $\left[\mathrm{Cd}(\mathrm{TBA}) \mathrm{Cl}_{2}\right]$ complex (Figure S9) was carried out in the temperature range $0-900^{\circ} \mathrm{C}$ under nitrogen atmosphere. The complex is stable up to $150^{\circ} \mathrm{C}$ and three major steps in the weight loss are observed: The 54, $9 \%$ mass loss $(54,6 \%$ theo) corresponding to the first and second steps of decomposition which appeared within the temperature ranges of $150-210$ and $210-275^{\circ} \mathrm{C}$, are ascribed to the loss of the organic ligand with two chloride atoms. The product of the second mass loss step is probably the residue cadmium sulfide (CdS). After $550^{\circ} \mathrm{C}, 15 \%$ weight loss observed was attributed to partial reactive sublimation of CdS. ${ }^{39}$

\section{Conclusion}

Cd(II) complex of TBA ligand has been synthesized. Crystal structure of TBA shows four independent molecules in asymmetric unit stabilized by dimeric N-H...S hydrogen bonded synthons assembled via C-H... $\pi$ interactions. Cd(II) complexes are formed by coordination competition between sulfur TBA and chloro ligands. Hirshfeld surface and fingerprint analyses reveal that $\pi \ldots \pi, \mathrm{N}-\mathrm{H} . . \mathrm{Cl}$ and $\mathrm{H}$. ..H interactions play an influential role in the crystal packing.

\section{Supplementary Information}

All additional information pertaining to the crystal structure of thiobenzamid TBA and its Cadmium complex (Figures S1, S2, S3 and S4) and characterization using, IR and electronic spectra of thiobenzamid TBA and its cadmium complex [Cd(TBA) $\left.\mathrm{Cl}_{2}\right]$ (Figures S5, S6 and S8), Raman spectra and TGA curve of $\left[\mathrm{Cd}(\mathrm{TBA}) \mathrm{Cl}_{2}\right]$ complex (Figures S7 and S9), selected bond lengths and bond angles of TBA and [Cd(TBA) $\mathrm{Cl}_{2}$ ] (Tables S1, S2) are given in the supporting information available at www.ias.ac.in/chemsci.

\section{References}

1. Sriram D, Yogeeswari P, Thirumurugan R and Pavana R K 2006 J. Med. Chem. 493448

2. Beraldo H and Cambino D 2004 Mini Rev. Med. Chem. 431

3. Kasuga N C, Onodera K, Nakano S, Hayashi K and Nomiya K 2006 J. Inorg. Biochem. 1001176

4. Xue S J, Zou J S and Yong H J 2000 Chin. Chem. Lett. 1119

5. Yong K S and Xue S 2006 Arkivoc 1063
6. Fengling C, Yanrui C, Hongxia L, Xiaojun Y, Jing F and Yan L 2006 Chin. Sci. Bull. 512201

7. Jensen O E, Lawesson S O, Bardi R, Piazzesi A M and Toniolo C 1985 Tetrahedron 415595

8. Crowford P C, Gillon A L, Green J, Orpen A G, Podesta T J and Pritchard S V 2004 CrystEngComm 6419

9. Mouchaham G, Roques N, Imaz I, Duhayon C and Suffer J P 2010 Cryst. Growth Des. 104906

10. Mouchaham G, Roques N, Brandès S, Duhayon C and Suffer J P 2011 Cryst. Growth Des. 115424

11. Felloni M, Hubberstey $\mathrm{P}$, Wilson $\mathrm{C}$ and Schrőder $\mathrm{M}$ 2004 CrystEngComm 687

12. Pryadip D, Prasenjit M, Amrita G, Amal K M, Tanmay B, Sakdeb S and Amitava D 2011 J. Chem. Sci. 123175

13. Ashiq K, Poonam S, Rajnikant, Vivek K G, Naresh P and Rekha S 2016 J. Chem. Sci. 128185

14. Miah A R, Sarker J C, Rajbangshi S, Kabir S E, Ghosh S and Siddiquee T A 2014 Indian J. Chem. 53274

15. Salehi M, Amirnasr M and Mereiter K 2009 Transition Met. Chem. 34373

16. Souza P, Arquero A, García-Onrubia A, Fernández V, Leiva A M and Müller U 2014 Z. Naturforsch., B: Chem. Sci. 44946

17. Safin D A, Klein A, Babashkina M G, Noth H, Krivolapov D B, Litvinov I A and Kozlowski H 2009 Polyhedron 281504

18. Frasson E and Panatoni C 1960 Acta Cryst. 13893

19. Sheldrick G M 1997 In SHELXL-97 Program for Crystal Structure Refinement (Germany: University of Gottingen)

20. Farrugia L J 1999 J. Appl. Crystallogr. 32837

21. Brandenburg K 1998 In Diamond. Version 2.1 (Univ. of Bonn: Allemagne)

22. Macrae C E, Bruno I J, Chisholm J A, Edgington P R, Mc Cabe P, Pidcock E, Rodriguez-Monge L, Taylor R, Van de Streek J and Wood P A 2008 J. Appl. Crystallogr. 41466

23. Wolff S K, Grimwood D J, McKinnon J J, Turner M J, Jayatilaka D and Spackman M A 2013 In Crystal Explorer 3.1 (University of Western Australia: Western Australia)

24. Seena E B, Kurup M R P and Suresh E 2008 J. Chem. Crystallogr. $\mathbf{3 8} 93$

25. Mahmood-ul-Hassan K, Shahid H, Tashfeen A and Jason D M 2009 Acta Cryst. E65 1128

26. Mahmood-ul-Hassan K, Shahid H, Tashfeen A and Jason D M 2009 Acta Cryst. E65 1333

27. Mahmood-ul-Hassan K, Shahid H, Tashfeen A and Jason D M 2009 Acta Cryst. E65 1446

28. Andreeti G D, Domiano P, Gasparri G F, Nardelli M and Sgaarabotto P 1970 Acta Cryst. B26 1005

29. Stoyanova A E and Peyerimhoff S D 2002 Electrochim. Acta 471365

30. Yahyaoui S, Ben Hassen R and Ben Salah A 2002 J. Chem. Crystallogr. 32243

31. Babashkina M G, Safin D A, Fayon F, Rakhmatullin A I, Sokolov F D, Klein A, Krivolapov D B, Pape T, Hahn F E and Kozlowski H 2010 Dalton Trans. 398261

32. Suna X-Z, Huangc Z-L, Wangc H-Z, Yea B-H and Chena X-M 2005 Anorg. Z. Allg. Chem. 631919

33. Spackman M A and Jayatilaka D 2009 Cryst. Eng. Comm. 1119 
34. Spackman M A and McKinnon J J 2002 CrystEngComm 4378

35. Guo L, Wu S, Zeng F and Zhao J 2006 Eur. Polym. J. 42 1670

36. Majumder A, Rosair G M, Mallick A, Chattopadhyay N and Mitra S 2006 Polyhedron 251753
37. Brenmam J G, Siegrist T, Carrol P J, Stuczinsky M, Brus L E and Steigerwald M L 1989 J. Am. Chem. Soc. 111414

38. Pickett N I and O'Brien P 2001 Chem. Rec. 1467

39. Hardy A D, Sutherland H H, Vaishanav R and Worthing M A A 1995 J. Ethnopharmacol. 4917 